\title{
Filosofia y literatura: dos herramientas necesarias ante los retos de una nueva Ilustración
}

\section{Philosophy and Novel: Two Necessary Tools Before the Challenges of a New Enlightenment}

\author{
Asunción Herrera Guevara ${ }^{1}$ \\ Universidad de Oviedo (España)
}

Recibido: 02-06-16

Aprobado: 09-07-16

\section{Resumen}

El ciudadano global necesita deliberar sobre los nuevos fenómenos globales. Debe preguntarse hacia dónde nos encamina la globalización y cuáles son sus consecuencias. El presente trabajo propone dirigir la globalización hacia una nueva Ilustración. Esta nueva Ilustración tendría que alcanzar lo que toda Ilustración promete: la emancipación del hombre. Mostraré que la Filosofía y la Literatura son dos herramientas necesarias para reflexionar sobre los actuales problemas éticos y políticos y, por ende, para alcanzar la emancipación. La metodología empleada será un análisis hermenéutico de textos filosóficos y literarios con el fin de argumentar mi propuesta.

Palabras-clave: Deliberación, Filosofía, Globalización, Ilustración; Literatura, Modernidad, Modernización.

\footnotetext{
${ }^{1}$ (aherrera@uniovi.es). Doctora en Filosofía y Profesora Titular de Filosofía Moral en la Universidad de Oviedo. Investiga en temas relacionados con la igualdad, la razón, el sujeto desgarrado, la globalización, la hermenéutica de la existencia y el constructivismo en la filosofía contemporánea. Últimamente ha ampliado su campo de investigación hacia la Bioética.

Entre su actividad investigadora caben destacar, además de sus diferentes publicaciones de artículos y libros especializados - La ética en la espiral de la Modernidad (2000), La historia perdida de Kierkegaard y Adorno (2005), Ilustrados o bárbaros (2014) y la edición y participación en el libro De animales y hombres (2007)-, su estancia en Universidades extranjeras (Universidad de Turín, Universidad de Frankfurt, Universidad de Northwestern y Universidad Libre de Berlín) y sus contribuciones a Congresos Nacionales e Internacionales.
} 


\begin{abstract}
Global citizen needs to deliberative about the new global events. This citizen has to know the consequences of our current globalization. This paper proposes to target globalization towards a new Enlightenment. This new Enlightenment will have to achieve what all promises of the Enlightenment aim: the emancipation of the human being. I will show that Philosophy and Novel are two necessary tools. We can reflect on our ethical and political problems with the help of Philosophy and Novel in order to achieve emancipation. I will use a hermeneutical methodology on certain philosophical and literary texts in order to argue my proposal.
\end{abstract}

Key-words: Deliberation, Enlightenment, Globalization, Modern age, Modernization, Novel, Philosophy.

\title{
Introducción
}

El mundo es una controversia nos dice uno de los personajes al final de Luces de Bohemia (Valle Inclán 2006), la obra teatral más esperpéntica, realista y actual de nuestro gran teatro español. El personaje Pica Lagartos resume de forma surrealista, con tal aseveración, lo inexplicable de los sucesos del mundo. Ante la incógnita de si la viuda y la hija del gran Max Estrella se habrían suicidado, o habrían muerto asfixiadas accidentalmente por el tufo de un brasero, la sentencia de Pica Lagartos nos devuelve a la realidad: los acontecimientos inexplicables del mundo nos incitan a una disputa inacabable en busca del significado de todo lo acaecido. Pero qué difícil será vislumbrar el significado allí donde sólo encontramos lo absurdo, Don Latino responde con esa lógica a Pica Lagartos: el mundo es un esperpento, algo feo y grotesco.

Valle Inclán muere en 1936 dejándonos uno de los legados literarios más ricos del pensamiento del siglo XX: el esperpento. Es necesario deformar sistemáticamente la realidad, recargarla con sus rasgos más grotescos y absurdos. ¿Con qué fin? cabría preguntarse. A fin de explicar lo inexplicable: sólo desde lo absurdo encontraremos la posibilidad de dar sentido a lo que carece de ello.

Años más tarde la figura de un filósofo alemán retoma la lógica Valleincliana. Me refiero al pensador Theodor Adorno. Adorno junto con Horkheimer publicarán en 1947, por primera vez como libro, Dialéctica de la Ilustración. La complejidad de la obra ha permitido diferentes interpretaciones. Escrita en un momento histórico cruento y crucial para Occidente, si volvemos a leerla notamos su actual vigencia. Precisamente porque el mundo sigue siendo una controversia es necesario repensar nuestro mundo y su racionalidad, tal y como hicieron Adorno y Horkheimer a finales de los años cuarenta. 
No sólo la filosofía a lo largo de la historia ha reflexionado sobre el tiempo que nos ha tocado vivir; la literatura también ha sido una buena compañera de viaje en esta crítica a la racionalidad occidental. Precisamente esta es una de las tesis que recorren el presente artículo: nuestro mundo necesita reflexión, pensamiento y crítica. Los problemas a los que se enfrenta la ciudadanía global así lo requieren. Ciertas corrientes políticas y económicas parecen menospreciar la importancia de las humanidades en general, y de la filosofía en particular, como herramientas a la mano de una ciudadanía que pretenda mostrar lo grotesco del mundo, en aras de su emancipación.

Los ciudadanos del siglo XXI se sienten consternados y superados por unos acontecimientos globales como nunca antes hemos vivido: fuertes migraciones, conflictos bélicos, terrorismo internacional e irreversible crisis ecológica son algunos de ellos. Sin olvidar lo que palpita tras todos estos avatares: una pobreza a nivel mundial que sigue creciendo. Ante este panorama, al sujeto sólo le queda la posibilidad de reflexionar para provocar una acción que revierta la dirección de ciertos acontecimientos.

En el terreno filosófico Martha Nussbaum ha sido una de las pensadoras que más ha profundizado en la relación entre filosofía y literatura, y en la importancia de las humanidades para el desarrollo de la deliberación ética. Tanto en El cultivo de la humanidad (Nussbaum 2005) como en Sin fines de lucro. Por qué la democracia necesita de las humanidades (Nussbaum 2010), la autora expone la necesidad de un diseño curricular universitario intercultural $\mathrm{y}$, por lo tanto, la urgencia de incorporar las artes y las humanidades, como fuente de recursos morales, en todo proyecto educativo.

El argumento principal que desarrolla Nussbaum para justificar su reclamo lo podemos encontrar en una obra anterior, La fragilidad del bien (Nussbaum 1995). La autora relaciona la deliberación ética con el método denominado equilibrio perceptivo. Este método recoge dos elementos deliberativos centrales de la teoría aristotélica: la phantasía y la teoría de la acción. Lo importante para Nussbaum es mostrar que "la teoriorización ética se realiza mediante un diálogo reflexivo entre las intuiciones y creencias del interlocutor o lector y una serie de concepciones éticas complejas, que se proponen para su estudio" (Nussbaum 1995: 38). Este sería el procedimiento que se realiza en el equilibrio perceptivo. Apoyándose en Aristóteles, afirma que "la mayoría de la personas cuando se les pide una generalización, realizan afirmaciones que no hacen justicia a la complejidad y el contenido de sus verdaderas opiniones" (Ibidem: 39). Si esto es así, necesitan descubrir lo que verdaderamente piensan y lo conseguirán "cuando, mediante la reflexión y el diálogo con los demás, hayan llegado a un ajuste armonioso de sus opiniones individual y colectivamente, se habrá alcanzado la verdad ética según entiende Aristóteles” (Ibidem: 39). 
El equilibrio perceptivo nos permite llegar a la verdad ética tras una reflexión, diálogo y un ajuste armonioso. ¿Qué papel juega la literatura en este proceso de deliberación práctica (ética y política)? Nussbaum considera que las novelas y especialmente las tragedias ofrecen grandes posibilidades deliberativas. Afirma la utilidad de trabajar con textos de este tipo "orientando al interlocutor en la elucidación y valoración de la postura compleja de otra persona [...] sobre un problema determinado. Ello permite un cierto distanciamiento con respecto a los propios prejuicios teóricos" (Ibidem: 39).

Siguiendo esta línea argumentativa afirmará que "el arte literario es más filosófico que la historia, porque la historia se limita a mostrar 'qué sucedió', mientras que las obras literarias nos muestran 'las cosas tal como podrían suceder' en la vida humana" (Nussbaum 1997: 29).

Apoyándome en esta concepción de Nussbaum, mantendré la importancia de utilizar los textos literarios a la hora de alcanzar una correcta deliberación práctica.

La deliberación, sobre los grandes dilemas éticos de nuestro tiempo, debería ser una tarea de todos los sujetos que en el mundo occidental estamos llamados a reflexionar. Intencionadamente hago hincapié en los ciudadanos globales de un primer mundo, quienes tienen cubiertas sus necesidades básicas. Sería falaz y engañoso exigir deliberación a quién tiene que preocuparse por conseguir una renta mínima para poder subsistir. Hecha esta apreciación vuelvo a insistir en la capacidad deliberativa que deberíamos ejercer el resto de ciudadanos globales, los que sí podemos permitirnos el lujo de pensar. Como ciudadanos globales capaces debemos ejercer esta tarea reflexiva. ¿Estaríamos todos los ciudadanos capacitados para ello? ¿Querrían todos esos sujetos dedicar su tiempo a la deliberación? Estas han sido dos preguntas que siempre se han formulado los detractores de la democracia deliberativa. Sus respuestas han sido contundentes: ni todos están capacitados, ni todos quieren perder su tiempo en deliberar sobre todo.

Para dar la vuelta a esta postura, y responder con un sí a las dos preguntas anteriores, me detendré en una obra de Azorín, La voluntad, escrita en 1902. Situémonos: dos de sus personajes, el maestro Yuste y el joven Azorín, pasean y conversan en una tarde primaveral. El maestro llevado por sus divagaciones le recuerda a Azorín que de igual modo que los niños tienen sus juguetes, los hombres también los tienen: "Platón, Aristóteles, Descartes, Spinosa, Hegel, Kant, son los grandes fabricantes de juguetes...La metafísica es, sí, el más inocente y el más útil de todos" (Azorín 1982: 101). Podría parecer que Yuste está pensando en un juego elitista reservado a aquellos que se llaman filósofos. Pero a continuación narra un cuentecillo que derrumba el elitismo: dos viajeros, de aspecto totalmente contrapuesto -uno gordo, otro flaco- viajan juntos y solos en un vagón, se ponen a platicar familiarmente; su conversación deja traslucir 
cierta resignación y melancolía filosófica. "Creo que la vida es triste" sentencia uno, "creo que es aburrida" responde el otro; "no conocemos la realidad" replica el primero, "no conocemos nada" tercia el segundo; "nadie conoce el noumenos" sentencia el gordo, "yo no conozco el noumenos" confirma el flaco; "sólo los fenómenos son reales" acuerdan los dos viajeros. Se despiden al final del viaje convencidos de que no conocen el noumenos, "uno era un filósofo kantiano; otro un empresario de barracas de feria" (Ibidem: 102).

El relato de Azorín ejemplifica de manera sarcástica como los dilemas importantes de nuestro tiempo son compartidos por todos. Seas filósofo kantiano o empresario de barracas de feria debes ejercer tu autonomía pública, deliberar y ser copartícipe en la construcción de las leyes que nos damos a nosotros mismos. Es el momento de dar una respuesta a la sentencia de Pica Lagartos "el mundo es una controversia".

Con la ayuda de la filosofía y de la literatura - dos juguetes inocentes y útiles- mostraré, en el presente trabajo, un diagnóstico de nuestro momento histórico y una reflexión sobre lo que debemos cambiar para revertir ciertos procesos, que nos conducen a una nueva barbarie como la que denunciaron en su momento Adorno y Horkheimer. En un primer punto, con la ayuda de la obra de teatro Calígula de Camus, explicaré lo fallidas que han sido nuestras experiencias ilustradas (1); en un segundo apartado, mostraré cómo la actual globalización es una continuación de la fallida modernidad que pretendiendo liberar a los hombres, los conquistó. En esta tarea me guiarán las novelas de Joseph Conrad El corazón de las tinieblas y La conciencia de Zeno de Italo Svevo (2); a continuación, vislumbraré una salida hacia la emancipación, si adoptásemos una teoría democrática diferente a la que tenemos. Interpretaré en esta clave la obra de teatro Doce hombres sin piedad (3); y por último, reflexionaré, con la ayuda de la Antígona de Sófocles, de Residencia de quemados de Hernández y de Morsamor de Valera, sobre el tipo de ciudadano que necesitamos para controlar y deliberar sobre los riesgos globales inevitables, que hemos de asumir en nuestro tiempo (4).

\section{Ilustración o barbarie}

Durante el siglo XX, y en la actualidad, el pensamiento ha aceptado la clasificación epocal que aparece en un texto de Foucault que lleva por título “¿Qué es la Ilustración?” (1999). El pensador francés menciona tres etapas configurativas para nuestra civilización: premodernidad, modernidad y posmodernidad. Si vamos a los escritores clásicos de cada época, vemos claramente cuáles son los rasgos que caracterizan cada momento histórico. 
En la época premoderna, las tragedias de Sófocles o Eurípides, o las reflexiones de Aristóteles o los estoicos, están plagadas de cuestiones relacionadas con la felicidad. En un mundo donde todos los sujetos debían ocupar su lugar se enseña, precisamente, a asumir el papel que a cada individuo le corresponde; sin esta asunción difícilmente se podía alcanzar la felicidad. De igual modo, el sentido teleológico de la felicidad está muy presente. Aristóteles en su Ética a Nicómaco explica cómo el verdadero fin de la naturaleza humana está en alcanzar su télos. Todos partimos de una naturaleza no educada y perseguimos alcanzar una naturaleza humana tal y como debiera ser si siguiera su télos. Las virtudes, tales como díke (justicia) o philía (amistad), nos van a ayudar en semejante tarea ética. Esta concepción ética en nada tiene que ver con el individualismo moderno. No se trata de conseguir individualmente mi télos. La tarea está dentro de la polis; hasta tal punto es así que yo debo poner mi libertad al servicio de ella. Tal asunción no se vive como una imposición o dominio de la totalidad sobre nuestras vidas (esta interpretación sería claramente moderna); todo lo contrario, mi felicidad va unida al conocimiento del lugar que debo ocupar en la polis para asegurar el bien común.

Situados en cualquier momento histórico, la acción política y moral siempre ha necesitado legitimarse. La acción política busca la aquiescencia de la ciudadanía. En la Atenas del siglo V, los aristoi eran los llamados a ser ciudadanos. Las acciones políticas de la Ciudad-Estado debían buscar legitimidad ante sus aristoi, debían justificar su coerción y buscar el reconocimiento de sus instituciones. Desde Platón y Aristóteles hasta llegar a la época medieval, con el dominio del pensamiento escolástico, la legitimación estatal se realiza mediante una argumentación ontológicamente fundada. A saber, se apela a un orden natural, anterior e inmutable, que justifica el orden terrenal. Sólo cabe un estado justo reflejo de ese orden previo.

Estamos ante un único Gran Relato de emancipación que legitima la acción política y en paralelo la acción moral. Esta forma de legitimación conduce a afirmar la existencia de un "Estado justo" que imita el orden natural, un estado educador y perfeccionista que interfiere directamente en la vida buena de sus ciudadanos. El "Estado justo" sabe lo que es el bien y lo promueve entre su ciudadanía. Este es otro de los rasgos fundamentales de la premodernidad.

Antes del inicio de la modernidad, a finales del medievo, se abandona este enmarque político (Habermas 1981). Surge, en El príncipe (Maquiavelo 1986), la tesis realista de la autolegitimación del Estado. El poder se regirá por la lógica de la dominación y mantendrá una clara neutralidad ética. El Gran Relato de emancipación lo encontramos, en este período, en la ética que seguirá siendo un reflejo del orden natural y, en este caso, divino.

Hemos de esperar a la modernidad para encontrar en el Leviatán (Hobbes 1989) un nuevo modelo legitimista. Hobbes abrirá el camino al enfoque 
contractualista: del pacto surge la justicia y la legalidad. En la ética también se comienza el giro moderno. Se cuestiona que la legitimidad ética resida en un orden natural; la verdad ética, la corrección normativa, no se descubre, se construye, se consensua. En paralelo se cuestionará la existencia de un sólo Gran Relato de emancipación: el discurso religioso, que encuentra la legitimidad en el orden divino, habrá de competir con la ciencia moderna y con un discurso filosófico que se emancipa de la teología. Son los individuos modernos los que han de construir no sólo su propia idea de bien, sino la idea de justicia. Esta será una de las tesis que intentarán imponerse dentro de la Ilustración. La Ilustración es -como dirá Kant en “Respuesta a la pregunta: ¿Qué es la Ilustración?”- la salida del hombre de su culpable minoría de edad:

Minoría de edad es la imposibilidad de servirse de su entendimiento sin la guía del otro. Esta imposibilidad es culpable cuando su causa no reside en la falta de entendimiento, sino de decisión y valor para servirse del suyo sin la guía de otro. Sapere aude! ¡Ten valor de servirte de tu propio entendimiento! Tal es el lema de la Ilustración (Kant 1999: 63).

De este modo, en una modernidad crecidita, nos topamos de lleno con uno de los acontecimientos más deslumbrantes que dará paso a una nueva época; me refiero a la Ilustración. Tres son sus grandes cabezas: los principios de la revolución francesa (libertad, igualdad y fraternidad), la ciencia moderna con sus dos revoluciones científicas cruciales (la encabezada por Galileo, Kepler y Copérnico a finales del siglo XVI, y principios del XVII; y la posteriormente encabezada por Darwin en el XIX) y una teología ilustrada que permite el inicio de la secularización del poder estatal (separación Iglesia/Estado) y de una progresiva secularización social. Con todos estos ingredientes, no sólo se exigirá una salida de la minoría de edad a la hora de reflexionar sobre temas morales y de justicia, sino que el discurso de los derechos del hombre y del ciudadano y el Imperio de la ley, que no de los hombres, se impondrán como sustrato de la nueva sociedad ilustrada.

La Ilustración ha de emancipar y liberar a los hombres. Pero como sentenciaron Adorno y Horkheimer en Dialéctica de la Ilustración, "la Ilustración, en el más amplio sentido de pensamiento en continuo progreso, ha perseguido desde siempre el objetivo de liberar a los hombres del miedo y constituirlos en señores. Pero la tierra enteramente ilustrada resplandece bajo el signo de una triunfal calamidad" (Adorno y Horkheimer 1994: 59). Con estas palabras, los pensadores frankfurtianos inician su indagación sobre la causa por la que la humanidad, "en lugar de entrar en un estado verdaderamente humano, se hunde en un nuevo género de barbarie" (Ibidem: 51). Es cierto que el pesimismo de los autores se enmarca en las postrimerías de la Segunda Guerra Mundial, pero precisamente el momento histórico que viven les permite 
hacer un análisis, tan agudo como radical, sobre la dialéctica de la Ilustración. Son capaces de mostrar cómo la Ilustración desde sus orígenes nace plagada de contradicciones y paradojas. La más incuestionable será su alianza con el dominio. Una Ilustración que pretende emancipar seguirá un camino contrario al aliarse con el totalitarismo, con la metafísica de la violencia. La razón instrumental, clave de la modernización occidental y herramienta de la idea de dominio, impondrá su lógica en el espacio sociopolítico y ético. En este punto crucial reside el origen de nuestra culpa. Para redimirnos, la Ilustración necesita ilustrarse a sí misma, perder su momento de violencia y permitir que los sujetos alcancen su verdadera emancipación.

Adorno y Horkheimer describieron magistralmente esta primera Ilustración fallida. Introdujeron ciertas claves para trastocar la situación de un mundo dominado por el terror, pero casi después de 70 años podemos afirmar que el mundo sigue siendo una total calamidad.

La modernidad del siglo XX intentó una segunda Ilustración. Los movimientos por los derechos civiles en EEUU, la revolución estudiantil del 68 junto con las emergentes reflexiones críticas sobre ecologismo o animalismo, son los componentes centrales de esta segunda pulsión ilustrada. Casi 50 años después seguimos atisbando los mismos problemas, pero incluso más agudizados. Problemas de género en Occidente y en el resto del mundo no occidental, junto a una crisis ecológica sin precedentes, sacuden nuestras conciencias. Este segundo intento de Ilustración también puede ser calificado de fallido.

A partir de los años 80 comienza la última etapa de la que nos habló Foucault, la posmodernidad. Sobre la existencia o no de una ruptura verdadera con la modernidad se ha discutido y se sigue discutiendo. No entraré en tal debate, sólo quisiera subrayar la hermenéutica que asumo: el único sentido válido de posmodernidad no viene de la mano de una ruptura con una etapa anterior; por el contrario, la posmodernidad es una respuesta moderna ante lo grotesco y feo del mundo. Somos posmodernos en la medida en que mostrando las grietas y fisuras de nuestras anteriores ilustraciones fallidas, queremos completar el proyecto de la Ilustración (Habermas 1988). Necesitamos ilustrar a la Ilustración para poder saltar a una tercera Ilustración no fallida. Esta es mi hermenéutica de la posmodernidad.

¿Por qué fallaron las anteriores Ilustraciones? Encontramos respuestas filosóficas y sociológicas de todo tipo, pero quisiera dar una respuesta deteniéndome en una obra de teatro de Camus, Calígula. La obra se estrena en París en 1945. Curiosamente, en el mismo momento que Adorno y Horkheimer concluyen Dialéctica de la Ilustración. Al igual que la obra de los frankfurtianos, la obra de Camus esquiva la implacable barrera que le impone el tiempo, y llega hasta nosotros con fuerza y vitalidad. 
Una obra de teatro que recrea la lógica y la vida de un personaje como Calígula es capaz de ejemplificar la lógica fallida del hombre ilustrado. A través de la Vida de los doce Césares de Suetonio, nos enteramos de que un hombre como Calígula, que sólo fue emperador tres años, diez meses y ocho días, ha pasado a la historia no por sus acciones como príncipe, sino por las que fueron propias de un monstruo. Suetonio las relata pormenorizadamente y se detiene en cada uno de los hechos que pusieron en evidencia su perverso sadismo. La obra de Camus reafirma esta imagen y, al mismo tiempo, consigue explicar la lógica que subyace detrás de las acciones del emperador. El emperador es la máxima figura del poder en ese momento. La utilidad del poder, como nos dice el propio Calígula, consiste en dar oportunidades a lo imposible: se trata de hacer posible lo que no lo es. Si se diera el caso, si se hiciera posible lo que no es, la felicidad se habría alcanzado. Calígula en su insatisfacción permanente funciona con esta lógica. Reclama a Helicón que le consiga la luna. Pero en la última escena de la obra, a punto de morir a mano de sus conspiradores, se queja de no haber conseguido la luna. Bastaría que lo imposible fuera para poder haber sido feliz y, consecuentemente, para poder haber sido libre.

Esta misma lógica la encontramos en el espíritu del hombre ilustrado. Para alcanzar su verdadera emancipación, su salida de la minoría de edad, bastaba con que lo imposible fuera. ¿Qué es ese imposible que anhela el espíritu moderno? Si fuese la posibilidad del bien, el sujeto esperanzado de la modernidad no habría instrumentalizado, cosificado, aritmetizado o capitalizado todo lo que toca. En términos filosóficos, no hubiese convertido la modernidad en un proceso arrollador llamado modernización. Pero lo imposible, que anhelaba el sujeto ilustrado, se tradujo en el absoluto dominio de lo desconocido, de lo otro, de la naturaleza. Para el caso es lo mismo, de una forma o de otra, la lógica totalitaria de las dos Ilustraciones fallidas han deseado un imposible destructivo para con el hombre y en nada emancipador.

La actual globalización neoliberal, ni ética ni políticamente defendible, es un paso más dado por la modernización. Veamos el caso.

\section{El corazón de las tinieblas y La conciencia de Zeno}

La globalización puede ser vista como un proceso que "designa la escala ampliada, la magnitud creciente, la aceleración y la profundización del impacto de los flujos y patrones transcontinentales de interacción social. La globalización remite a un cambio o transformación en la escala de la organización humana que enlaza comunidades distantes y expande el alcance de las relaciones de poder a través de regiones y continentes de todo el mundo" (Held y McGrew 2003: 13). Como los propios autores de esta caracterización señalan, no 
podemos pensar que tras la globalización se esconde una sociedad global armoniosa. Es cierto que nuestra sociedad ha acelerado, casi vertiginosamente, el impacto de determinados flujos transcontinentales de interacción social, política, económica y, por supuesto, ecológica; pero no es menos cierto que esta aceleración, como diría Nancy Fraser, no se ha enmarcado justamente. Tal problema de enmarque trae unas consecuencias.

Por un lado, no todos los países han participado como corresponsables en el fenómeno globalista y consiguientemente tampoco se han beneficiado de la supuesta bonanza económica y social que reporta la globalización. De este modo, el flujo de capitales y tecnología derivados de una globalización como la defendida por el FMI, no se ha dado en todos los continentes ni en todos los países. Existen tres grandes bloques responsables del proceso y beneficiados por el mismo, me refiero a Europa, el pacífico asiático y parte del continente americano. Por otro lado, aunque no deja de ser una gran paradoja o una ironía de la historia, los países no responsables ni beneficiados por la globalización sí han sufrido los efectos perversos y adversos de la misma. Este fenómeno puede darse con total impunidad, precisamente, porque la globalización no ha sido enmarcada justamente.

Siguiendo el modelo de justicia propuesto en Escalas de justicia (Fraser 2008), el fallido enmarque del fenómeno global ha conducido a una mala redistribución de la riqueza, a un reconocimiento fallido y a una representación política fallida. Si realmente vivimos en una sociedad global con procesos cada vez más globales que locales y con riesgos claramente globales (piénsese en la globalidad de los riesgos ecológicos), entonces será necesario que todo el proceso se enmarque en una justicia global o transcultural. No podemos seguir dando repuestas a los problemas desde una justicia local, si los problemas ya no son locales. En el mejor de los casos cabría hablar de problemas glocales (Beck 2001). En una justicia global, como señala Fraser, es necesario repensar los tres ámbitos tradicionales de la justicia: el ámbito que responde al quién de la justicia, es decir, a los sujetos afectados por esa justicia; el espacio que responde al qué, es decir, en qué dimensión ontológica debemos ser justos; y, por último, el ámbito del cómo, encontrar cómo implementar esa justicia en las instituciones.

Ante la vertiginosa aceleración de lo global, el quién se debe responder atendiendo no sólo a unos ciudadanos determinados de un estado nación; por el contrario, será la ciudadanía global el sujeto de esta justicia internacional. A esta ciudadanía se la debe justicia en tres espacios ontológicos: el de la redistribución de la riqueza, el del reconocimiento cultural y el de la representación política. Y, por supuesto, las instituciones necesarias para implementar este modelo de justicia internacional han de ser globales y transculturales. 
Una justicia transnacional, como la propuesta por Fraser, sí protegería a todos los sujetos "sometidos a la(s) estructura(s) de gobernación que regula(n) las áreas relevantes de la interacción social” (Fraser 2008). ¿Hemos alcanzado este modelo de justicia? Estamos muy lejos de esta sociedad fraseriana. Numerosos ciudadanos globales sufren en sus propias carnes las consecuencias que adoptan estructuras de gobernación que toman decisiones globales y, sin embargo, estos mismos ciudadanos no reciben igual consideración. Pensemos tan sólo en dos casos flagrantes. El primero tiene que ver con la migración y el tema de los refugiados; el segundo con la industria agroalimentaria global.

Nadie pone en duda el problema ético y político que se encuentra tras el drama personal que viven migrantes y refugiados. Existen leyes internacionales aprobadas en defensa de unos derechos humanos inalienables que deberían proteger a todos los seres humanos, quienes sufren unas condiciones de vida extremadamente indignas y peligrosas. La mayor parte de la migración huye del hambre, y la mayoría de los refugiados huyen de conflictos bélicos o persecuciones a causa de su no reconocimiento étnico, sexual, político o cultural. Los tratados y las leyes internacionales están firmados por numerosos estados nación y, a pesar de ello, asistimos a la indiferencia, el rechazo, o a la falta de operatividad, ante el problema humanitario, de esas mismas naciones que suscriben los tratados. En ocasiones, escuchamos a estados de la UE -que reconocen esos tratados internacionales-justificar su inacción como una cuestión de prioridad nacional o de soberanía nacional. ¿A qué estamos asistiendo? Claramente a una doble moral y a una doble política. La globalización ha encandilado al turbocapitalismo, pero no se ha hecho extensiva a la defensa real de los derechos humanos y de la democracia. Los sujetos globales se someten a decisiones económicas transnacionales que modifican sus formas de vida, pero, por el contrario, no se ven protegidos por una justicia correctamente enmarcada en esta nueva sociedad global. Se permite la deslocalización de la producción, el libre mercado, la libre circulación de mercancías y de capitales, ahora bien, ante las consecuencias de una auténtica globalización de los derechos humanos, nos volvemos provincianos y justificamos nuestros cierres y alambradas. Más aún, ni siquiera permitimos un verdadero desarrollo de estructuras internacionales de justicia, que garanticen la dignidad de todos los ciudadanos globales.

Es evidente que este es un ejemplo central para denunciar, como ya he señalado, que la globalización neoliberal no es ni ética ni políticamente defendible.

El otro caso al que me quería referir tiene que ver con la industria alimentaria y las biotecnologías; me refiero a la producción y consumo de alimentos transgénicos. Vivimos en la época de la biotecnología (Rifkin 1999) y asistimos al florecimiento de un jardín biotecnológico (Mendiola 2006). Nuestra tarea será estudiar los monstruos, las plantas transgénicas, con el fin 
de no quedar simplemente fascinados. Es necesario "arrojar una sombra de duda ante las verdades de la ciencia [...] porque lo que aquí está en juego es si queremos vivir en este jardín biotecnológico" (Mendiola 2006: 23-24). Los alimentos transgénicos siguen mostrando la doble cara de la globalización. Estamos ante una producción global, una comercialización global por parte de grandes oligopolios, y la asunción de riesgos en relación a este tema también son globales. Sin embargo nos volvemos a topar con una incoherencia: la producción, el mercadeo y el consumo globalizado de los transgénicos no se correlaciona con una justicia transnacional, que proteja a los sujetos afectados, tanto a los consumidores de Occidente como a los agricultores de América del Sur. Escasa información, deficiente inversión en bioseguridad, o mal etiquetado de los productos, son algunos de los problemas a los que han de enfrentarse los consumidores (Riechmann 2004). Pérdida de su poder adquisitivo, invasión de sus tierras e imposición de los deseos de las grandes multinacionales son algunos de los males que padecen los agricultores de América latina. Problemas y males derivados de un mal enmarque de la globalización.

La falta de apuesta por una justicia transnacional como la propuesta en el modelo de Fraser, y los ejemplos de justicia fallida que vemos en nuestro actual mundo globalizado, nos muestran claramente que no nos movemos en la dirección correcta, si queremos alcanzar un tercer intento de Ilustración no fallido (Herrera 2014). Podríamos afirmar todo lo contrario, seguimos la estela de una modernización que nos ha imposibilitado la realización de nuestros proyectos ilustrados.

Antes de dar por finalizado este apartado, explicaré el título del mismo en donde se citan dos obras literarias. La primera entronca claramente con la idea de una globalización como proceso que perpetúa la modernización capitalista. Este fenómeno no comenzó en el siglo XX. Las fuertes colonizaciones son el inicio del movimiento globalizador. Nada mejor que El corazón de las tinieblas (Conrad 2005) para justificar tal afirmación. El protagonista y marinero, Marlow, que realiza una travesía por un río tropical en busca del jefe de una explotación de marfil llamado Kurtz, ejemplifica el viaje de nuestra conciencia ilustrada. Navegamos por la globalización con nuestro espíritu ilustrado, Marlow viaja con su espíritu victoriano. Marlow descubrirá los horrores de una colonización, y nosotros acabamos encontrando las entrañas de una desalmada globalización. A lo largo de su trayectoria, y a medida que Marlow conoce la brutalidad con la que los colonos tratan a los nativos africanos, ya no podrá defender esa distinción, que realiza al comienzo del relato, entre colonizadores y conquistadores. Los primeros los encontramos en el colonialismo europeo, su administración no era simplemente opresión, sino que lograron establecer un flujo económico bidireccional entre la metrópoli y los territorios coloniales; los segundos eran conquistadores "y para ello sólo se necesita la fuerza bruta [...] 
se apoderaban de todo lo que podían por simple ansia de posesión, era un pillaje con violencia, un alevoso asesinato a gran escala y cometido a ciegas, como corresponde a hombres que se enfrentan a las tinieblas" (Conrad 2005:132). En su viaje iniciático, Marlow se percatará de la sinrazón de la distinción. Un colonizador como Kurtz, exitoso traficante de marfil, no sólo representa la ambición de toda colonización, sino que muestra claramente como todo intento de ilustrada colonización se transforma en conquista brutal, transformando al propio sujeto ilustrado en una bestia que roza la locura. Al final de la novela, el moribundo Kurtz en el barco de Marlow a su regreso a casa "gritó en susurros a alguna imagen, a alguna visión; gritó dos veces, un grito no más fuerte que una exhalación: ‘¡El horror! ¡El horror!'” (Conrad 2005: 237-238). Tal vez el grito de Kurtz sea su momento de redención -aquí caben diferentes interpretaciones-, nunca sabremos con total seguridad que Conrad hiciera gritar a Kurtz estas palabras con un fin moralizante. La mera denuncia del horror, el hecho de mostrar las grietas del corazón de las tinieblas es lo importante.

Tal vez alguien encuentre exagerado la comparación de los horrores coloniales con las disfunciones morales y políticas de la globalización, pero en este punto quiero recordar una sentencia -tomada de Freud- que Adorno repite en sus obras: “en la exageración está la verdad”. Aunque tal vez no esté exagerando, pensemos en ciertas imágenes brutales y desalmadas que vemos todos los días, ante ellas bien pudiéramos gritar ¡El horror!

Este artículo no pretende moralizar y, por lo tanto, no voy a pedir redención ante los atropellos de la globalización neoliberal; pretendo hacer hincapié en la necesidad de reflexionar, con la ayuda de la filosofía o de la literatura, sobre las contradicciones y paradojas de una globalización como la que estamos viviendo. Un proceso que cada vez se aleja más del espíritu ilustrado.

Para acabar el apartado voy a detenerme en la otra obra titulada La conciencia de Zeno (Svevo 2004). En esta novela, el personaje central Zeno es un mediocre comerciante obsesionado con reflexionar sobre su vida. Alentado por su psicoanalista, escribe sobre sus vivencias y busca la "curación". La curación de una vida mediocre sumida en la mentira y el engaño de un matrimonio fallido. En esa búsqueda de sanación escribe su autobiografía. A medida que nos adentramos en la novela, nos percatamos de la debilidad moral de Zeno. Es incapaz de reconocer en su personalidad y en los valores que adopta el origen de sus males. Todo lo contrario, achaca toda su "enfermedad física y mental" al vicio de fumar, e intentará, una y otra vez, abandonar este hábito. El personaje de Zeno tras una vida fallida encuentra su curación después del estallido de la Gran Guerra. La guerra le alcanza, él deja de fumar; su vida dará un giro tras el inicio de la guerra. Ya entrado en años y con el pesar de lo acontecido, Zeno se percata de su gran error: considerar que la vida, con sus episodios de dolor o de amor, es una enfermedad de la que 
hay que curarse. Zeno siempre se ha sentido enfermo cuando en realidad tan solo vivía. La conclusión a la que llega es bastante aterradora: la destrucción del hombre será su curación:

La vida actual está envenenada hasta las raíces. El hombre ha ocupado el lugar de los árboles y los animales y ha envenenado el aire [...] Hay una amenaza de esa clase en el aire. El resultado será una gran riqueza..., en el número de hombres. Cada metro cuadrado estará ocupado por un hombre. ¿Quién nos curará de la falta de aire y espacio? [...] Tal vez gracias a una catástrofe inaudita, producida por los instrumentos, volvamos a la salud [...] Habrá una explosión enorme que nadie oirá y la Tierra, tras recuperar la forma de nebulosa, errará en los cielos libre de parásitos y enfermedades (Svevo 2004: 466-467).

La obra de Svevo publicada en 1923 ya nos avisa acerca del verdadero peligro que se cierne sobre el hombre y la Tierra: el propio hombre. Zeno ha sido su propia enfermedad, esa que pretendía extirpar. El hombre en general es la enfermedad de la Tierra. Si seguimos con un proceso desalmado de modernización, alejado del verdadero espíritu de la Ilustración, acabaremos autodestruyéndonos. No es una tesis catastrofista, sino realista. Para confirmarla solo debemos leer los documentos sobre la salud del planeta. Como algunos ecologistas, biólogos y científicos de la tierra nos recuerdan, todavía estamos a tiempo de realizar una "retirada sostenible" del dominio indiscriminado hacia la naturaleza y, añado, hacia lo diferente.

En el siguiente apartado pondré un ejemplo de cambio necesario. $\mathrm{Si}$ queremos sujetos y ciudadanos que reflexionen sobre nuestras fallidas ilustraciones debemos, como sociedad y como Estado, asumir una teoría democrática que vaya más allá de la representación. La deliberación juega un papel central. Sin deliberación, no hay posibilidad de cambio, no hay posibilidad de convencer a los ciudadanos sobre el giro que debe dar nuestra modernidad.

\section{Doce hombres sin piedad}

Modernización, Ilustración, democracia y capitalismo forman un cuarteto consistente desde los inicios de nuestra época moderna. Dos ilustraciones fallidas, que han sobrevalorado a la racionalidad instrumental y ninguneado a la racionalidad comunicativa, por ende, habrían de amistarse con una democracia más formal que real y más representativa que deliberativa.

No podemos obviar que nuestra teoría política y democrática presenta un doble origen: liberal y republicano (Habermas 2004). La democracia occidental no se entiende sin unos principios liberales arraigados de forma contundente en la obra de John Locke y sin el republicanismo rousseaniano. 
Es cierto que en Aristóteles ya se perfila un tipo de republicanismo, pero será el republicanismo iniciado por Rousseau el que deje más impronta en nuestra actual teoría política. Dos pivotes centrales de nuestra democracia muestran el carácter dual de la misma. Por un lado, cuando pensamos en una democracia estamos visualizando un Estado de derecho que garantiza a sus ciudadanos los derechos subjetivos modernos (derechos civiles y políticos y derechos sociales y económicos, principalmente); se trata de garantizar el Imperio de la ley que no de los hombres. Por otro lado, tampoco concebimos la democracia sin el démos, sin la soberanía popular que reside en el Parlamento. El primer componente es claramente liberal, el segundo republicano. Como dice Habermas:

En la historia de la filosofía política es un hecho que estas dos fuentes de legitimación del Estado democrático de derecho aparecen compitiendo entre sí. Liberalismo y republicanismo no están de acuerdo sobre dónde situar la prioridad en la jerarquía de la fundamentación: si en la 'libertad de los modernos’ o en la 'libertad de los antiguos'. ¿Qué es primero los derechos subjetivos de libertad de los ciudadanos en la moderna sociedad económica, o los derechos de participación política de los ciudadanos en el Estado democrático? (Habermas 2004: 142).

Si pasáramos una encuesta a la ciudadanía, preguntándoles acerca de sus preferencias democráticas, es decir, si prefieren un sistema garantista de sus derechos o un sistema que les permita la participación política y, por lo tanto, ser copartícipes en la construcción de las leyes, la mayor parte nos contestaría que no quiere ni puede prescindir de una de las opciones democráticas señaladas. Evidentemente, es una falaz elección. No concebimos un sistema democrático sin derechos, pero tampoco sin participación política. Con otras palabras, autonomía privada (derechos subjetivos modernos) y autonomía pública (soberanía popular) se necesitan mutuamente para garantizar la legitimidad del Estado democrático. Esto no quiere decir que en nuestros sistemas actuales no prevalezca una tendencia sobre la otra. Hay estados más constitucionalistas, donde la garantía democrática y la legitimidad del Estado reside centralmente en la Constitución, en esa Ley de leyes que recoge los derechos subjetivos modernos; pero también nos encontramos con estados más parlamentaristas, que insisten en el papel central del Parlamento donde reside la soberanía popular a la hora de legitimarse.

Supongamos que vivimos en un estado capaz de conjugar ambos momentos de legitimación. Si este fuese el caso, además de estar dotado de una constitución que garantizase los derechos de su ciudadanía, nos encontraríamos con un parlamento menos representativo y más deliberativo. Me explico, es cierto que nuestras democracias intentan conjugar ambos modelos; pero no es menos cierto, que las actuales democracias representativas carecen de uno 
de los elementos centrales del republicanismo: la deliberación. Se nos podría argumentar que en el Parlamento se delibera, pero todos sabemos que en nuestros parlamentos más que deliberar se negocia. Deliberación y negociación no son la misma cosa en relación a la salud democrática de un país.

La democracia, debido a la complejidad y extensión de las actuales sociedades, ha de ser representativa pero esto no debería impedir una verdadera deliberación. La deliberación es necesaria para garantizar, dentro de sus propias limitaciones, la corrección normativa de las decisiones que adopta la soberanía popular. Esto no quiere decir que la calidad del proceso a la hora de tomar decisiones sea condición suficiente para garantizar la corrección del resultado, pero sí es una condición necesaria. La deliberación debe ser entendida como la posibilidad del cambio endógeno de preferencias que resulta de la comunicación (Stokes 2001). Con la deliberación se podrían aunar racionalidades, forzar o estimular un modo de justificar demandas, mejorar las cualidades morales o intelectuales de los participantes o provocar un mayor consenso (Fearon 2001).

En definitiva, la deliberación no sólo es necesaria sino compatible con nuestras democracias representativas. No mengua a nuestro modelo democrático, todo lo contrario, le añade valor democrático proveniente de la tradición republicana.

Si como vengo mostrando en el presente trabajo, se necesita reflexionar sobre lo que hemos hecho mal para contar con dos ilustraciones fallidas y lo que debemos hacer para alcanzar una tercera Ilustración, la reflexión necesita de los otros, necesita de la deliberación. Auténtica deliberación en el Parlamento, en la esfera pública formal, y también en la esfera pública informal (medios de comunicación, asambleas, etc.) de mayor alcance para la ciudadanía.

No se trata de deliberar sobre todo ni de cualquier forma. Evidentemente, es necesario acordar unas condiciones formales que garanticen el proceso. Los deliberativistas insisten en este punto (Martí 2006).

Como ejemplo de una buena deliberación tomaré la obra de teatro Doce hombres sin piedad (Reginald Rose 2006). La obra trata sobre el juicio de un joven acusado de parricidio. Lo interesante, para el tema tratado, es la deliberación de los doce miembros del jurado para determinar la culpabilidad o no culpabilidad del joven en cuestión. El caso parece fácil de resolver, las pruebas apuntan a un veredicto de culpabilidad. Pero la evidencia dejará paso a la duda razonable tras una larga y auténtica deliberación. Sólo el jurado número ocho vota, en una primera votación, no culpable. Él llevará la batuta de la deliberación y convencerá al resto del jurado para cambiar su decisión. El jurado número ocho desmontará todos los argumentos del resto de los miembros del jurado. Es evidente que sin la deliberación, y si el método hubiera sido la mera agregación de preferencias -en este caso de votos-, el veredicto hubiera sido bien distinto; habría prevalecido la culpabilidad. 
Como ya he explicado en otros trabajos (Herrera 2014), la obra de Rose recoge puntos cruciales del proceso deliberativo. Se constata las deficiencias epistémicas de los miembros del jurado a la hora de deliberar y cómo estas mismas serán subsanadas. Por ejemplo, el jurado número dos no se atreve a expresar sus verdaderos pensamientos; el jurado número tres no es sincero al no confesar su odio hacia el acusado, le recuerda al rebelde de su hijo, prefiere su condena -como sublimación del castigo hacia su hijo- antes que alcanzar la verdad del caso; el jurado número cinco analiza el caso de forma personal por el hecho de haberse criado en el mismo barrio que el acusado; el jurado número siete no asume sus responsabilidades comunicativas, desea acabar cuanto antes para poder asistir a un partido de béisbol; para colofón, el miembro número diez acaba confesando sus prejuicios racistas. La obra nos muestra como los participantes en la deliberación no cumplen unas condiciones epistémicas óptimas. A pesar de ello, el jurado número ocho socavará los prejuicios de la mayoría y revertirá las condiciones epistémicas de la deliberación. "Comenzarán a ser sinceros, se tomarán en serio las objeciones de los demás, darán razones para justificar las opiniones expresadas y adoptarán la perspectiva del bien general buscando un veredicto justo" (Herrera 2014: 141).

Con el análisis de la obra de Rose pretendo mostrar la necesidad de recordar que la salud democrática no se sustenta tan sólo en el principio de mayoría o la votación; la regla de unanimidad o la deliberación son tan democráticas como las anteriores. Y aunque hoy en día, la deliberación es reivindicada con fuerza por corrientes políticas cercanas a alguna forma de republicanismo, no olvidemos que importantes liberales también la tuvieron muy presente, como es el caso de Stuart Mill. Las teorías políticas de hoy que no olvidan la deliberación, aún aceptando gran parte del legado liberal, defienden una forma de republicanismo kantiano (Habermas y Rawls 1998), o de republicanismo liberal (Pettit 1999).

La deliberación tanto en la esfera pública formal como en la informal, tanto en el Parlamento como entre los ciudadanos, es un elemento crucial para reflexionar sobre la posibilidad de iniciar una nueva época, que nos permita completar el proyecto emancipatorio de la modernidad.

En el siguiente apartado haré referencia al tipo de ciudadanía que se necesita para alcanzar esa tercera Ilustración.

\section{Antígona, Residencia de quemados y Morsamor}

Que la salud democrática se mide en gran parte por la importancia que en la esfera pública se da a la deliberación, no es algo novedoso. Comencé el apartado primero del presente artículo con una referencia a la época premoderna 
y a su búsqueda de la felicidad. Igualmente lo acabaré retomando la época clásica. Analizando sus textos encontramos como valor destacado el papel de la deliberación. Aristóteles reflexiona magistralmente sobre este concepto. Ya el pensador peripatético nos enseña, en sus obras, que la verdadera deliberación moral no es la presente en la deliberación cotidiana de quien vacila sobre cómo ejecutar una acción. La deliberación moral es reflexiva y, por lo tanto, irá unida a la phrónesis (prudencia). La deliberación práctica debe ir unida a una "regla correcta" o "recta razón" (orthóslogos) que llamamos phrónesis. La buena deliberación se acomoda a lo que encuentra de forma flexible, y respeta la complejidad de la situación. Así actúa la persona prudente. Ser prudente no se define con una mera enumeración de cualidades cognoscitivas, es necesario tener en cuenta el carácter, la educación de los deseos y la flexibilidad de estos últimos (Nussbaum 1995). La elección deliberativa la define Aristóteles como capacidad situada entre lo intelectual y lo pasional que comparte la naturaleza de ambos: deliberación desiderativa o deseo deliberativo: "Y como el objeto de la elección es algo que está en nuestro poder y es tema de deliberación y deseable, la elección será también un deseo deliberado de cosas a nuestro alcance; porque cuando decidimos después de deliberar deseamos de acuerdo con la deliberación" (Aristóteles 1113a 9). Una violenta batalla entre la razón y los sentimientos es muestra de inmadurez ética, y no de un carácter bien formado.

Una deliberación sin phrónesis nos puede conducir a un conflicto insalvable como el que mostró Sófocles en la Antígona. Los dos personajes centrales, Antígona y Creonte, son ejemplos de inmadurez ética, su carácter mal formado les impide alcanzar la eudaimonía (felicidad), o lo que es lo mismo, una vida buena no fallida.

Recordemos el conflicto planteado por Sófocles, Creonte es el gobernante que vela por la leyes de la ciudad, Antígona es la mujer que vela por las leyes de la familia. Ha muerto Polinices, el hermano de Antígona y pariente de Creonte, ha muerto como traidor de la ciudad al comandar una expedición invasora y, por lo tanto, Creonte, siguiendo sus leyes, no puede permitir que se dé sepultura a su cadáver. Por el contrario, Antígona al seguir la ley de la familia desea y decide enterrar a su hermano enfrentándose con Creonte. Ambos personajes simplifican su universo valorativo -Creonte al considerar que lo justo y lo bueno es sólo lo que beneficia a la ciudad, Antígona al situar lo justo y lo bueno en función de la relación familiar- y por ende evitan responsabilidades contrapuestas (Nussbaum 1995). Ambos ciudadanos se obcecan en su decisión y no tienen en cuenta la otra perspectiva del problema: Creonte se muestra miope ante los vínculos familiares y afectivos, Antígona ante la ciudad. 
El personaje regulador lo encontramos en Tiresias y en ciertos llamamientos del coro. Tiresias, el anciano y ciego sacerdote de Apolo -dios relacionado con el orden y el límite- manifiesta con sus palabras la buena deliberación. El anciano sacerdote pide a Creonte que reflexione y ceda, pues "¿qué hazaña es volver a matar a un muerto?" (Sófocles 1981: 150) le increpa sabiamente. Más aún, le advierte de que si no es capaz de rectificar pagará con un muerto de sus entrañas. Siguiendo el buen decir de Tiresias, el corifeo aconseja a Creonte no perseverar en el error. La buena deliberación es relacionada, por el viejo sacerdote, con la capacidad de conceder, con el abandono de la terca obstinación y con la flexibilidad. Ni Creonte ni Antígona rectificarán; ambos, presos de su inmadurez ética, no consiguen el equilibrio y la flexibilidad que se necesita para vivir como un sujeto civilizado.

Antígona morirá sin retractarse, aunque sí se dará cuenta del conflicto que vive y de cómo su empecinamiento la ha ofuscado e impedido ver algo real: a pesar de su fervor por los vínculos familiares, y la ley de la familia, ella también necesitará de la ciudad para que oficien su cadáver. Creonte sí se arrepiente e incluso pretende rectificar su error, pero ya es demasiado tarde. Su hijo Hemón, enamorado de Antígona, ante la tragedia de esta se quita la vida; de igual modo actúa Eurícide, esposa de Creonte y madre de Hemón, se suicida tras la muerte de su hijo. El arrepentimiento de Creonte llega tarde. Las palabras del corifeo al final de la tragedia aleccionan a los ciudadanos: "Con mucho la sensatez es lo primero para la felicidad. Es necesario no cometer ninguna impiedad contra los dioses. Las palabras altaneras de los soberbios, pagando su deuda en grandes golpes, les enseñan con la vejez a ser prudentes" (Ibidem: 159).

La simplicidad del ethos tanto de Creonte como de Antígona conduce inevitablemente a la tragedia. Ambos personajes de la tragedia griega son un buen ejemplo del tipo de ciudadano que no necesitamos para revitalizar nuestras actuales democracias y sociedades occidentales. Todo lo contrario, hemos de educar a la ciudadanía en la buena deliberación.

Un ejemplo de cómo educar a los ciudadanos a ser valientes y "desencastillarse" lo encontramos en Residencia de quemados (Hernández 2016). Novela que en una de sus partes nos cuenta con un lenguaje cargado de neologismos y arcaizante, la historia de Ruta, la princesa de los Arcanitas. Ruta realizará un viaje plagado de aventuras a través de tres imperios -el imperio de los Bestiarios, el de los Bucolitas y el de Tierra Negocia- con el único propósito de convencer a sus ciudadanos, con la ayuda del Relato total, de la capacidad que tienen para "desencastillarse", para dejar de ser súbditos irreflexivos y ser ciudadanos emancipados. Para la princesa Ruta es irrefutable que todo sistema o "mangoneado" se apoya no sólo en sus dirigentes, sino también en sus muchos colaboradores. Es preciso sacar de la adormidera a esos ciudadanos que colaboran con el "mangoneado". La falta de voluntad, y las enfermedades 
"idiosomáticas" pueden ser una de las causas de la irreflexión y falta de madurez ética de los "encastillados" colaboracionistas. Una de las arengas de Ruta ilustran su propósito de convencer, como "retesadora de mentes", en la posibilidad de emancipación, en la posibilidad de salir de la culpable minoría de edad:

\begin{abstract}
Desteñíos de adhesión y bañaos de antiguos esos chorros de indecencia y veneno que os visten, cual cumplidera... destiranizaos... destetaos de dicho pezón purulento... desgranujaos... deshistoriad la obstinación que mamasteis por la que os destináis en el futuro de un pasado [...] Habéis pagado con vuestros impuestos mi educación en la Aldea de la Razón, y como veis, orgullosos poneos de lo aprendido, que no hice mal rendimiento del tiempo. En dicha correría exploré el saber, amé y perdí mi corazón, pero volví para desencastillaros (Hernández 2016:147-148).
\end{abstract}

Es cierto que hoy en día no necesitamos un personaje como Ruta, pero sí necesitamos muchos ciudadanos con fortaleza ética como Ruta para convencer y "desencastillar" en la búsqueda de esa tercera Ilustración.

La buena deliberación guiada por la phrónesis nos permitiría deliberar con flexibilidad y sin obcecación sobre las fallidas ilustraciones que hemos vivido y, lo más importante, sobre el nuevo proyecto de Ilustración. Los ciudadanos capaces de deliberar pueden convencer y ser convencidos con la fuerza de los mejores argumentos. ¿Alcanzaremos el resultado deseado? Para responder a esta pregunta nada mejor que acudir al final de la novela Morsamor (Valera 2003). Fray Miguel, también llamado Morsamor cuando se aventura por el mundo, es convencido por el Padre Ambrosio del engaño en que vive quien busca en la vida los honores que las hazañas traen consigo, quien sólo se preocupa por el resultado final de sus acciones. Este había sido el caso de Fray Miguel. Retirado del mundo se lamenta de no haber conseguido pasar a la historia por sus hazañas. Su desazón y vanidad es tal que será capaz de pactar mefistólicamente con el Padre Ambrosio, consiguiendo en su lecho de muerte regresar al mundo como el caballero Morsamor y vivir como un héroe. Tras sus andanzas despierta en su lecho y se siente engañado por quien con artes esotéricas le permitió danzar en busca de hazañas, cuando tal vez solo las haya soñado. La respuesta del Padre Ambrosio es toda una lección moral:

Baste para mi intento de convencerte de la aptitud y del poder que hay en ti, tanto para lo bueno como para lo malo, la ilimitada confianza que en mí pusiste y la constancia y el valor con que te sujetaste a mis conjuros, arrostraste pruebas tremendas y no retrocediste, lleno de terror, ante mis mágicas operaciones. Quien fue capaz de todo esto es capaz también de todas las hazañas y digno de las victorias y de los triunfos. Sólo de la fortuna, sólo de las circunstancias exteriores, y no de la virtud del alma, depende que en realidad se logren o que sólo se logren en sueños (Valera 2003: 274). 
Fray Miguel se convenció con la lección vivida de las veraces palabras del Padre Ambrosio, cabe esperar de los ciudadanos del siglo XXI el mismo convencimiento. No hacen falta héroes que busquen hazañas y triunfos, sino ciudadanos que sepan vivir su autonomía privada y pública dentro de sociedades democráticas en donde la buena deliberación nos permita construir y creer en la posibilidad de un nuevo proyecto ilustrado.

Una de las pretensiones de este artículo es haber podido mostrar que la filosofía y la literatura -parafraseando a Azorín- son dos de los más inocentes y útiles juguetes para llevar a cabo esta tarea. 


\section{Referencias bibliográficas:}

Adorno, T y Horkheimer, M. (1994). Dialéctica de la Ilustración. Madrid: Trotta.

Aristóteles (1970). Ética a Nicómaco, trad. de M. Araujo y J. Marías. Madrid: Instituto de Estudios

Políticos.

Beck, U. (2006). La sociedad del riesgo global. Madrid: Siglo XXI.

Camus, A. (2005). Calígula. Madrid: Alianza Editorial.

Conrad, J. (2005). El corazón de las tinieblas. Madrid: Cátedra.

Fearon, J. D. (2001). La deliberación como discusión. En J. Elster (compilador), La democracia deliberativa (pp. 65-95). Barcelona: Gedisa.

Foucault, M. (1999). “¿Qué es la Ilustración?”. En Estética, ética y hermenéutica, vol. III (pp. 335-353). Barcelona: Paidós.

Fraser, N. (2008). Escalas de justicia. Barcelona: Herder.

Habermas, J. (1981). La reconstrucción del materialismo histórico. Madrid: Taurus.

-(1988). Ensayos políticos. Barcelona: Península.

- y Rawls, J. (1998). Debate sobre el liberalismo político. Barcelona: Paidós. -(2004). Tiempos de transiciones. Madrid: Trotta.

Held, D y McGrew, A. (2003). Globalización/Antiglobalización. Barcelona: Paidós.

Hernández García, A. (2016). Residencia de quemados. Oviedo: Luna de Abajo. Herrera Guevara, A. (2014). Ilustrados o bárbaros. Madrid: Plaza y Valdés.

Hobbes, T. (1989). Leviatán. Madrid: Alianza Universidad.

Kant, I. (1999). "Respuesta a la pregunta: ¿Qué es la Ilustración?”. En En defensa de la Ilustración (pp. 63-73). Barcelona: Alba Editorial.

Maquiavelo, N. (1986). El príncipe. Madrid: Alianza Editorial.

Martí, J. L. (2006). La república deliberativa. Madrid: Marcial Pons.

Martínez Ruíz, J. (Azorín) (1982). La voluntad. Madrid: Editorial Castalia.

Mendiola, I. (2006). El jardín biotecnológico. Madrid: Los libros de la Catarata.

Nussbaum, M. C. (1995). La fragilidad del bien. Madrid: Visor.

-(1997). Justicia poética: la imaginación literaria y la vida pública. Barcelona: Andrés Bello.

-(2005). El cultivo de la humanidad: una defensa clásica de la reforma en la educación liberal. Barcelona: Paidós.

-(2010). Sin fines de lucro. Por qué la democracia necesita de las humanidades. Madrid: Katz.

Pettit, P. (1999). Republicanismo. Barcelona: Paidós.

Riechmann, J. (2004). Transgénicos: el haz y el envés. Madrid: Los libros de la Catarata. 
Rifkin, J. (1999). El siglo de la biotecnología. Barcelona: Crítica.

Rose, R. (2006). Twelve Angry Men. New York: London: Penguin Classics.

Sófocles (1981). Teatro completo. Barcelona: Bruguera.

Stokes, S. C. (2001). "Patologías de la deliberación”. En J. Elster (compilador), La democracia deliberativa (pp. 161-183). Barcelona: Gedisa.

Svevo, I. (2009). La conciencia de Zeno. Barcelona: Random House Mondadori. Valera, J. (2003). Morsamor. Sevilla: Fundación José Manuel Lara.

Valle Inclán, R. M. (2006). Luces de Bohemia. Madrid: Espasa Libros. 
